\title{
CLASSIFICATION AND ZONING OF WATER QUALITY FOR THREE MAIN RIVERS IN BINH TRI THIEN REGION (CENTRAL VIETNAM) BASED ON WATER QUALITY INDEX
}

\author{
Nguyen Van Hop, Thuy Chau To, Truong Quy Tung \\ Chem. Dept., Hue College of Sciences, Hue University, \\ 77 Nguyen Hue Str., Hue, Vietnam
}

Received 02 April 2007

\begin{abstract}
Huong, Thach Han and Kien Giang rivers are the important surface water sources in Thua Thien Hue, Quang Tri and Quang Binh provinces, respectively (in Central Vietnam). The river water samples were taken monthly (from June 2001 to May 2002 for Kien Giang river and from January to December of 2004 for Thach Han and Huong rivers) at selected sites. The temperature, $\mathrm{pH}$, conductivity (EC), salinity, turbidity (TUR), $\mathrm{DO}, \mathrm{COD}, \mathrm{BOD}_{5}$, nitrate, ammonia, phosphate, total solids (TS), hardness, total dissolved iron, total coliform (TC), fecal coliform (FC) and sodium adsorption ratio (SAR) of water samples were analyzed. Water quality index developed by Bhargava (Bhargava-WQI) was modified and applied to assess water quality of the above mentioned rivers. Based on Bhargava-WQI, the classification and zoning of the rivers for beneficial uses were carried out. The results obtained show that the water quality index can be used as an efficient tool for the water quality management and water pollution control of the rivers.
\end{abstract}

Keywords: Bhargava; Water quality index.

\section{INTRODUCTION}

Huong river (Thua Thien Hue province), Thach Han river (Quang Tri province) and Kien Giang river (Quang Binh province) are the important sources of surface water in Binh Tri Thien Region (Central Vietnam). They supply water to all local activities including domestic water supply, industry, agriculture, navigation, tourism, aquaculture, especially Sugpo prawn culture in downstream area in the dry season ... However, those rivers are also the places into which the untreated wastes from local activities was discharged. The floods and salinity intrusion are problems to the rivers [5]. In order to manage water quality (WQ) and control water pollution more advantageously, an attempt to find out an efficient and simple method to assess WQ is essential to not only specialist, but also the community and decision policy makers.

In many countries in the world, to assess water quality, separate WQ parameters are analyzed and compared with the defined national standards of different uses. However, this is facing with difficulties because not all of the parameters can satisfy a certain purpose of use. For example, in Vietnamese Standard TCVN 5942:1995, the values of DO, suspended solids (SS) and total coliform (TC) of surface water in level A (reaching the standard of domestic water supply) and level B (not reaching the standard of domestic water supply and being used for other purposes) are $6 \mathrm{mg} / \mathrm{l}$ and $2 \mathrm{mg} / \mathrm{l} ; 20 \mathrm{mg} / \mathrm{l}$ and $80 \mathrm{mg} / \mathrm{l} ; 5.000 \mathrm{MPN} / 100 \mathrm{ml}$ and $10.000 \mathrm{MPN} / 100 \mathrm{ml}$, 
respectively. In a river (or one part of a river), DO is at the level A but SS and TC are under the level A. Whereas, in other river (or other part of a river) SS is at the level A; DO and TC are under the level A; or DO and SS are at the level A but TC is under the level A or even the level B. Therefore, it is very difficult to produce the assessment of water quality at level A or B. Moreover, based on the separate parameters we could be confused about the assessment of the temporal and spatial changing tend of WQ; the zoning and classification of WQ; the comparison of WQ in the rivers; and the interpretation of water quality to community. Above disadvantages can be overcome by using Water Quality Index - WQI [2, 7 - 9].

WQI is an aggregation parameter calculated on many WQ parameters according to a defined method [9]. WQI is scaled from 0 (the worst water quality) to 100 (the best water quality). The WQI model is first coined and applied in the USA in 1965 [9]. At present, there are over 30 kinds of WQI being used in many parts of the world [7]. The WQI model coined by Bhargava (in India) in 1983 [1, 2] is one of the simple models, easy to use in the developing countries. On the other hand, this model allows assessing WQ for both general (multipurpose) use and specific use (such as domestic water supply, agriculture and aquaculture etc.)

The goal of this study was to show the application of modified Bhargava WQI model to the WQ management, classification and zoning of the selected rivers in Binh Tri Thien (Central Vietnam).

\section{EXPERIMENTAL}

\subsection{Sampling}

Figure 1 shows the selected sampling sites stretching from the upper-part to lower-part of the Huong river (6 sites marked from $\mathrm{H} 1$ to $\mathrm{H} 6$ ), of the Thach Han river ( 8 sites marked from TH1 to TH8) and of the Kien Giang river (6 sites marked from KG1 to KG6).

At each of sampling sites, water samples are taken at 2 points (which are away from the both side of the river with a suitable distance). At each point, composite sample is collected at the two different depths of $50 \mathrm{~cm}$ and $100 \mathrm{~cm}$ of water column with the volume ratio 1:1. The sampling duration is from January, 2004 to December, 2004 in the Huong river and Thach Han river; from Jun, 2001 to May, 2002 in the Kien Giang river. The sampling is carried out once a month.

\subsection{Measurement and analysis of WQ parameters}

The parameters of temperature, $\mathrm{pH}$, turbidity (TUR), electric conductivity (EC), salinity (SAL), total dissolved solids (TDS), dissolved oxygen (DO) are measured at the field (by using WQC $22 \mathrm{~A}$ - TOA, Japan) at the two depths of $50 \mathrm{~cm}$ and $100 \mathrm{~cm}$ and then averaged.

Laboratory analysis of WQ parameters such as chemical oxygen demand (COD), biochemical oxygen demand $\left(\mathrm{BOD}_{5}\right)$, active phosphate $(\mathrm{PO} 4)$, nitrate $(\mathrm{NO} 3)$, ammonia $\left(\mathrm{NH}_{4}{ }^{+} / \mathrm{NH}_{3}\right)$, total solids (TS), hardness (according to $\mathrm{CaCO}_{3}$ ), total coliform (TC), fecal coliform (FC), K, Na and total dissolved iron are carried out according to the standard method of APHA [4].

\subsection{WQI calculation and classification of WQ}

\subsubsection{WQI calculation}

According to Bhargava model, WQI of the specific (or beneficial) use is calculated on the following formula [1]: 


$$
\text { WQI }=\left[\prod_{i=1}^{n} F_{i}\right]^{1 / n} \times 100
$$

where $F_{i}$, the value of sensitivity function of parameter $i\left(F_{i}=0,01 \div 1\right)$, is determined based on the graph of sensitivity function of parameter i (Fig. 2). The sensitivity function graphs are linear and established on the basis of national standards of WQ for each specific use. $n$, the quantity of selected parameters for each specific use (Table 1).

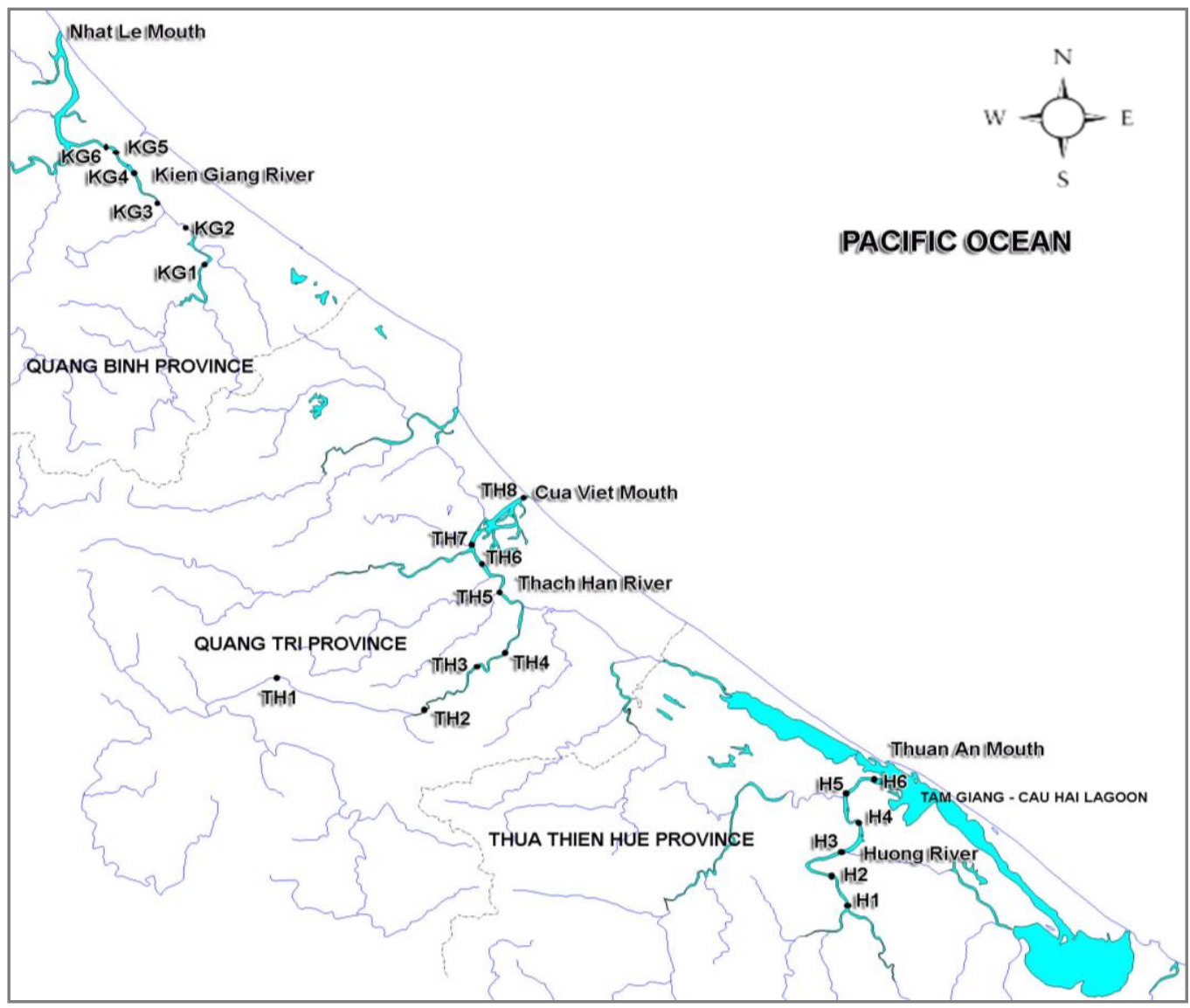

Fig. 1. Sampling sites in the selected rivers in this study.

Based on Bhargava WQI model, we adjust the selected parameters so that they are suitable for WQ of the rivers. General WQI can be worked out by averaging WQI of specific uses arithmetically including their suitable important factors. In this study, we assume that the importance of the specific uses is similar.

In comparison with Bhargava WQI model, WQI recommended by the United States - National Sanitary Foundation (NSF-WQI) is also calculated as follows [9].

$$
\mathrm{WQI}=\prod_{1}^{n} q_{i}^{w_{i}}
$$


where, $\mathrm{q}_{\mathrm{i}}$, sub-index of the $\mathrm{i}$ th determinant (between 0 and 100), determined from sub-index function for the $i$ th determinant; $w_{i}$, the weighting of the $i$ th determinant (between 0 and 1 ); $n$ : number of determinants in the index system $(\mathrm{n}=9)$. Determinants and their weightings (written in brackets) are DO (0.17), FC (0.15), pH (0.12), BOD5 (0.10), NO3 (0.10), PO4 (0.10), temperature (0.10), TUR $(0.08)$ and TDS $(0.08)$, respectively.
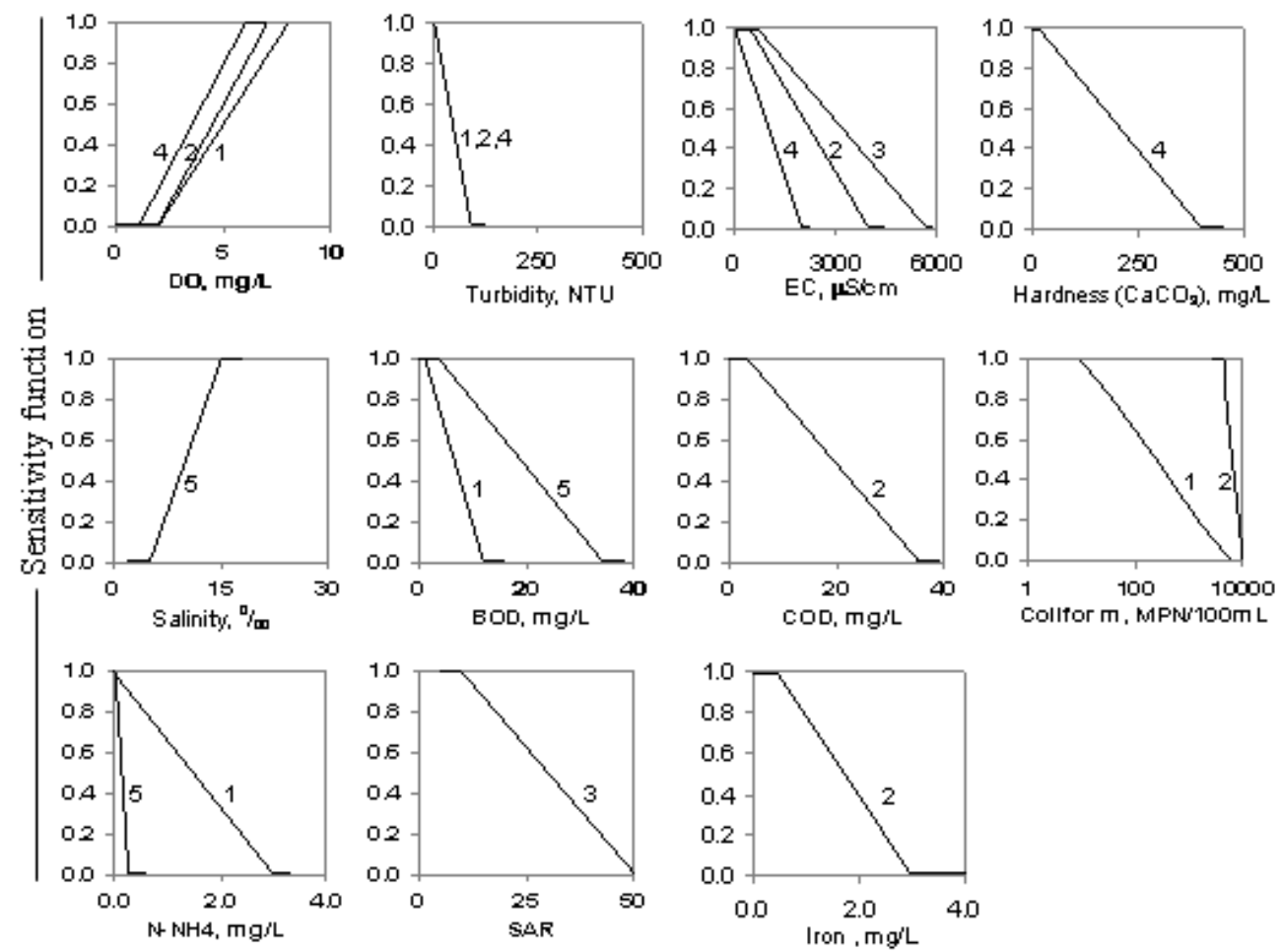

Fig. 2: Sensitivity functions of selected parameters for specific uses Symbols 1, 2, 3, 4, and 5 correspond to the specific uses showed in Table 1.

Table 1: Selected WQ parameters for specific uses .

\begin{tabular}{|c|c|c|c|}
\hline $\mathbf{N}^{\mathbf{0}}$ & Specific use & Selected parameters $^{\text {(a) }}$ & $\mathbf{n}$ \\
\hline 1. & Bathing, swimming & TUR, ammonia, TC, $\mathrm{BOD}_{5}, \mathrm{DO}$ & 5 \\
\hline 2. & Public water supplies ${ }^{(b)}$ & $\begin{array}{l}\text { TUR, COD, TC, DO, EC, ammonia, total } \\
\text { dissolved iron (c) }\end{array}$ & 7 \\
\hline 3. & Agriculture $^{(d)}$ & EC, sodium absorption ratio (SAR) & 2 \\
\hline 4. & Industry ${ }^{(e)}$ & TUR, EC, hardness & 3 \\
\hline 5. & Sugpo prawn culture & Salinity, ammonia, $\mathrm{DO}, \mathrm{BOD}_{5}$ & 3 \\
\hline
\end{tabular}

(a) Other WQ parameters (not showed in Table 1) of the rivers were much smaller than that required in Vietnam Standard; 
(b) In the second use (public water supplies), $\mathrm{BOD}_{5}$ and $\mathrm{Cl}^{-}$(used in Bhargava model) was replaced by $\mathrm{COD}$ and $\mathrm{EC}$, respectively, because the determination of COD is more precise than that of BOD5 when the values of BOD5 is lower than 1,5 ppm; EC is directly proportional to $\mathrm{Cl}^{-}$and measured more easily and rapidly;

(c) Total dissolved iron was only used for the calculation of WQI in the Kien Giang river because its concentration is usually high in this river;

(d) In the third use (agriculture), $\mathrm{Cl}^{-}$(used in Bhargava model) was replaced by EC, TDS (used in Bhargava model) was not used because EC is usually directly proportional to TDS in the rivers;

(e) In the fourth use (Industry), TDS (used in Bhargava model) was replaced by EC because EC is usually directly proportional to TDS in the rivers.

According to the Bhargava WQI and NSF-WQI system, the WQI score of a river in this study is zero, if the concentration of any heavy metals or persistent organic pollutants (POPs) is higher than permissible level specified in the national water quality standards.

\subsubsection{WQ classification}

According to the Bhargava model [1], the value of WQI ranges from 0 (the worst quality) to 100 (the best quality) and is categorized into 5 classes: Class I, $90 \div 100$ (very good); Class II, $65 \div$ 89 (good); Class III, $35 \div 64$ (medium); Class IV, $11 \div 34$ (bad); Class V, $1 \div 10$ (very bad). When the value of WQI is in Class I and Class II, the water quality of the rivers meets specific/general uses.

\section{RESULTS AND DISCUSSION}

\subsection{Variation in general WQI of rivers}

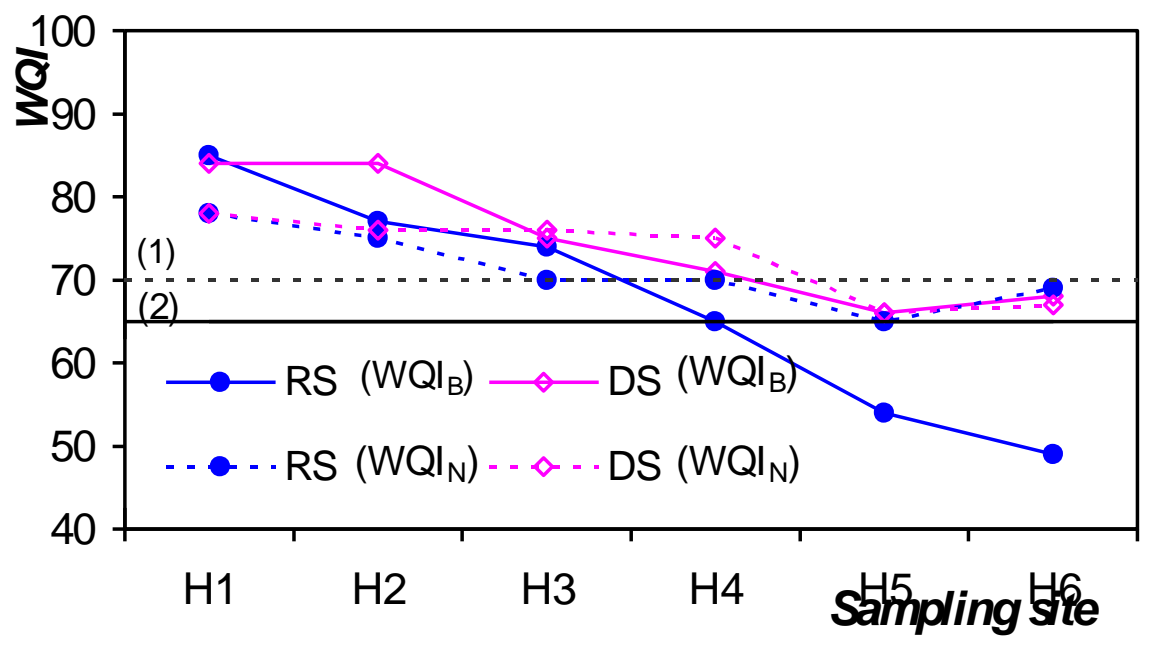

Fig. 3: Variation in General WQI values (WQI $I_{B}$ and $W Q I_{N}$ ) in Huong river in 2004 (rainy season - RS and dry season - DS). (1) Demarcating bounder line of good level (WQI = 71 - 90) and medium level (WQI = 51 - 70) according to NSF-WQI model; (2) Demarcating bounder line of good level $(W Q I=65-89)$ and medium level $(W Q I=35$ -64) according to Bhargava model. 
The variation in the general WQI of the Huong river in season (dry season - DS: January August and rainy season - RS: September - December) and in space (from H1 to H6) is showed in Fig. 3. $\mathrm{WQI}_{\mathrm{N}}$ is the general WQI worked out by $\mathrm{NSF}$ model and $\mathrm{WQI}_{\mathrm{B}}$ is the general WQI worked out by Bhargava model.

There is a closed correlation between the values of $\mathrm{WQI}_{\mathrm{N}}$ and $\mathrm{WQI}_{\mathrm{B}}$ with $\mathrm{R}=0.79$ at $\mathrm{H} 1$ site. The correlation is lower at the sites of H2 - H6 $(\mathrm{R}=0.34-0.57)$. Obviously, WQI calculated by NSF and Bhargava models produce the different reflection of the water quality of the Huong river. The obtained results in this study reveal that $\mathrm{WQI}_{\mathrm{B}}$ is a reflection of the $\mathrm{WQ}$ in downstream more reasonable than $\mathrm{WQI}_{\mathrm{N}}$. According to NSF model, WQ in the downstream area of the Huong river (H4 - H6) is good (or a good approximation in dry season). This means that the water can be used for general purposes. In fact, there is salinity intrusion into this area in the dry season, and therefore, the water can not be used for domestic activities and agriculture. Whereas, according to Bhargava model the water quality is medium in the dry season.

The comparison of $\mathrm{WQI}_{\mathrm{B}}$ with $\mathrm{WQI}_{\mathrm{N}}$ in Thach Han and Kien Giang rivers also results in the same conclusion. $\mathrm{WQI}_{\mathrm{B}}$ should be, therefore, used to evaluate WQ in the rivers which are subjected to the salinity intrusion in the dry season in Binh Tri Thien region.

\subsection{Classification and zoning of WQ}

The WQ classification and zoning for specific uses will be gave a lot of advantages to the water source management and exploitation. In reality, the parts of the rivers are being used for the various purposes (see Table 1). It is essential to classify and zone the WQ for the specific uses based on WQI. Table 2 shows the temporal and spatial variations of the WQI values of the rives for the general and specific uses. The WQ classification for the specific uses is presented in Table 3. Based on the similarity of the WQ class at the close sites (in Table 3), the zoning of the rivers is carried out and the water uses are suggested as showed in Table 4.

On the whole, the WQ of the rivers tends to decrease in downstream, especially in the dry season. This limits the scope of water use. The main cause to this problem is that the rivers receive the untreated wastes (liquid and solid) from the human activities along the course of the rivers. On the other hand, the wastes from aquaculture activities and salinity intrusion make contribution to the decrease of the water quality in the downstream.

The result of WQI calculated shows that when a selected parameter $i$ if $F_{i}=0.01$ (it mean that quality of parameter $\mathrm{i}$ is very bad because its value is higher than permissible level), the WQI calculated is at the medium level (III) or can be at the bad level (IV). As a result, WQ can not meet specific use. This clearly shows that WQI is the sensitivity reflection of the WQ of the rivers. However, WQ assessment based on WQI is restricted by the eclipse of the bad water quality parameters.

For specific uses, the parameters with typically mall values of $F_{i}$ (bad quality) are as follows:

- In the Huong river (Thua Thien Hue province): TURB (in the rainy season), TC and EC or SAL (in the dry season);

- In the Thach Han river (Quang Tri province): TURB (in the rainy season), TC, EC or SAL ( in the dry season) and ammonia (in the dry season at lower part of river);

- In the Kien Giang river (Quang Binh province): TURB, total dissolved iron (in the rainy season), COD, TC and EC or SAL (in the dry season). 
Table 2: WQI values of the rivers for the specific uses.

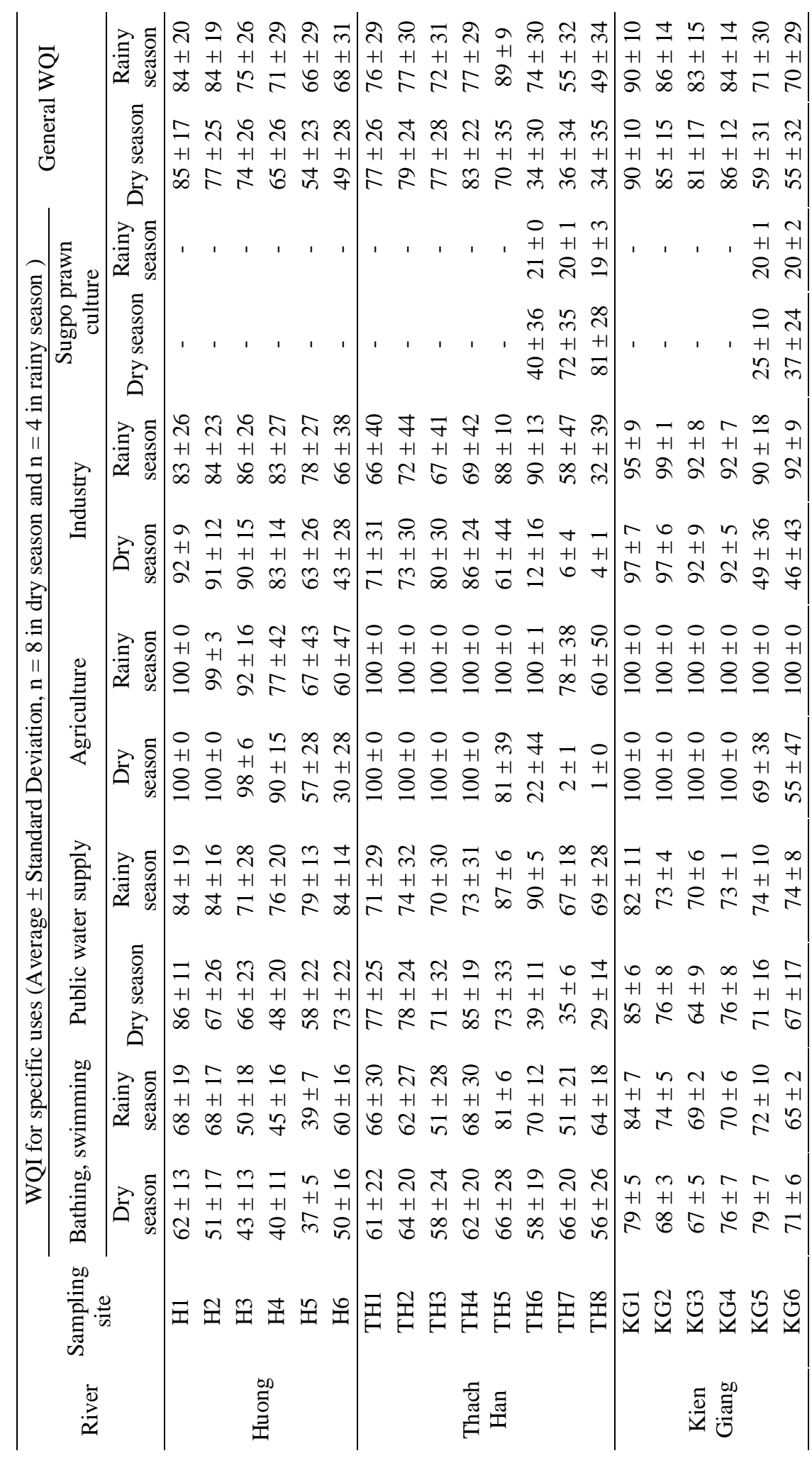


Table 3: Classification of the rivers.

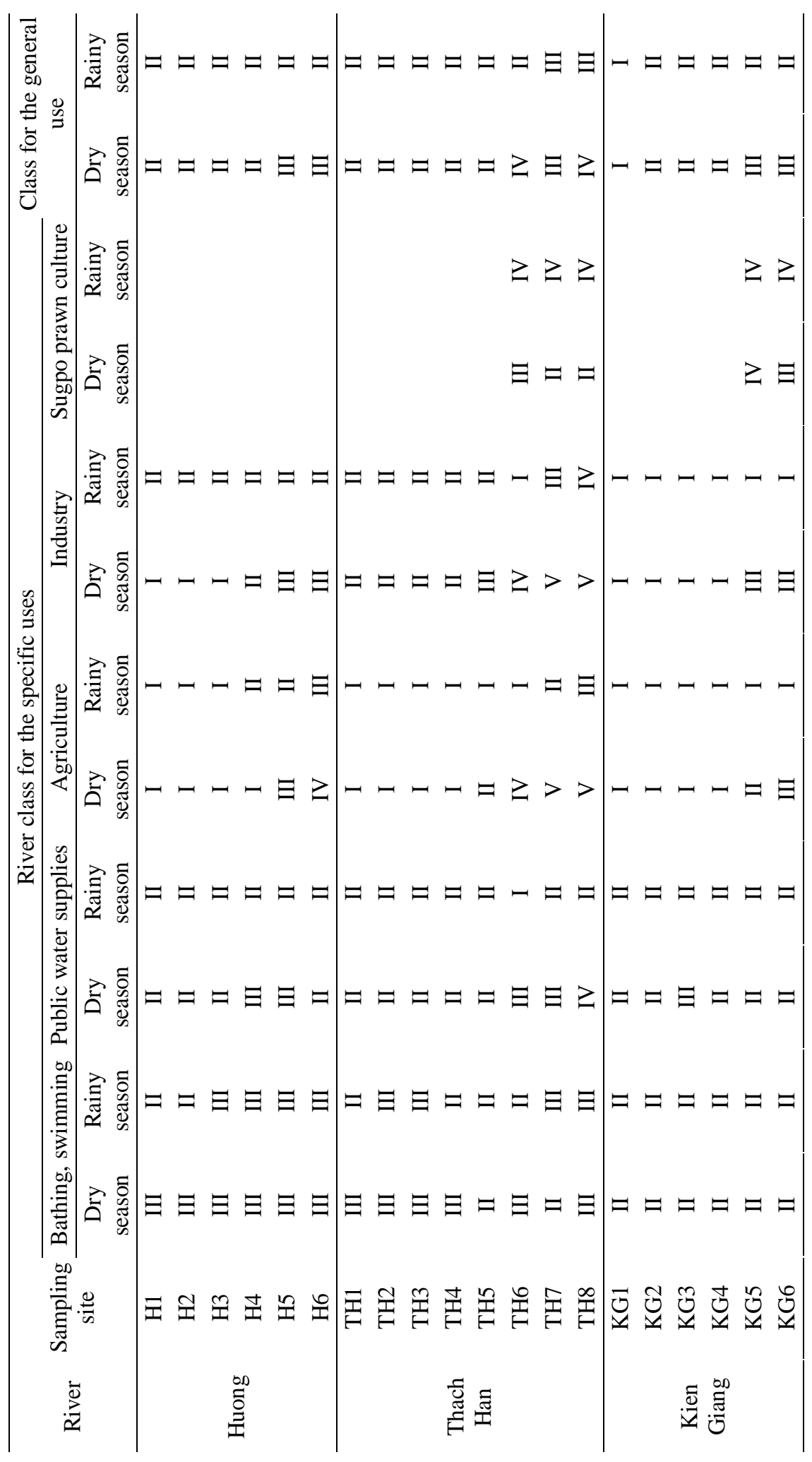


Table 4: Zoning of the rivers and suggestion of specific uses.

\begin{tabular}{|c|c|c|c|}
\hline \multirow{2}{*}{ River } & \multirow{2}{*}{ Zone $^{(*)}$} & \multicolumn{2}{|c|}{ Acceptable specific uses (WQI belonging to Class I or II only) } \\
\hline & & Dry season & Rainy season \\
\hline \multirow{3}{*}{ Huong } & $\mathrm{H} 1 \div \mathrm{H} 2-3$ & $\begin{array}{l}\text { Public water supplies, } \\
\text { industry, agriculture }\end{array}$ & $\begin{array}{l}\text { Bathing, swimming, public water } \\
\text { supplies, industry, agriculture }\end{array}$ \\
\hline & $\mathrm{H} 2-3 \div \mathrm{H} 4-5$ & Industry, agriculture & $\begin{array}{l}\text { Public water supplies, industry, } \\
\text { agriculture }\end{array}$ \\
\hline & $\mathrm{H} 4-5 \div \mathrm{H} 6$ & None & Public water supplies, industry \\
\hline \multirow{4}{*}{$\begin{array}{l}\text { Thach } \\
\text { Han }\end{array}$} & $\mathrm{TH} 1 \div \mathrm{TH} 3$ & $\begin{array}{l}\text { Public water supplies, } \\
\text { industry, agriculture }\end{array}$ & $\begin{array}{l}\text { Public water supplies, industry, } \\
\text { agriculture }\end{array}$ \\
\hline & TH3 $\div$ TH5-6 & $\begin{array}{l}\text { Public water supplies, } \\
\text { industry, agriculture }\end{array}$ & $\begin{array}{l}\text { Bathing, swimming, public water } \\
\text { supplies, industry, agriculture }\end{array}$ \\
\hline & TH5-6 $\div$ TH6-7 & None & $\begin{array}{l}\text { Bathing, swimming, public water } \\
\text { supplies, industry, agriculture }\end{array}$ \\
\hline & TH6-7 $\div$ TH8 & Sugpo prawn culture & Public water supplies \\
\hline \multirow{2}{*}{$\begin{array}{l}\text { Kien } \\
\text { Giang }\end{array}$} & KG1 $\div$ KG5 & $\begin{array}{l}\text { Bathing, swimming, public } \\
\text { water supplies, agriculture }\end{array}$ & $\begin{array}{l}\text { Bathing, swimming, public water } \\
\text { supplies, agriculture, industry }\end{array}$ \\
\hline & KG5 $\div$ KG6 & $\begin{array}{l}\text { Bathing, swimming, public } \\
\text { water supplies }\end{array}$ & $\begin{array}{l}\text { Bathing, swimming, public water } \\
\text { supplies, agriculture, industry }\end{array}$ \\
\hline
\end{tabular}

${ }^{(*)}$ H2-3, H4-5, TH5-6 and TH 6-7 are the sites between $\mathrm{H} 2$ and H3, H4 and H6, TH5 and TH6, TH6 and TH7, respectively.

At present, the water in the upstream of the Huong river $(\mathrm{H} 1-\mathrm{H} 3)$, Thach Han river (TH1 TH3) and Kien Giang river (KG1 - KG2) is used for domestic activities but the WQ is at second level (good). This is caused by the facts that the upper parts of the rivers are polluted with bacteria all along in the dry season and their turbidity increases caused by the corrosion and runoff from the upstream forests and coastal cultivation. The bacterial contamination of the upperparts of the Huong and Thach Han rivers leads to the pollution of river water, which is not good for bathing and swimming.

In the dry season, the salinity of water in the lower part of the Thach Han river increases because of the salinity intrusion. This is good for brackish water culture, specially, Sugpo prawn culture. Thao Long damp and My Trung damp restrict the salinity intrusion into the Huong river and the Kien Giang river. As a result, in the dry season, the water quality in the upper parts of the rivers is good for agriculture purposes (see Table 2 and 3).

\section{CONCLUSION}

Adjusted Bhargava WQI model has the sensitively reflection of the variation in WQ of the rivers in Binh Tri Thien region. WQI is the efficient tool for water quality management and water pollution control of the rivers. By using WQI, we easily inform the community and decision makers about water quality. Moreover, the classification and zoning of WQ based on WQI are favourable to the uses of water sources, to the establishment of WQ monitoring program in the future. In conclusion, there is a lot of advantage in using WQI, however, WQI is still a limitation on eclipsing the WQ parameter of poor quality. 


\section{REFERENCES}

1. Bhargava, D.S. (1983), Use of water quality index for river classification and zoning of Ganga River, Environmental Pollution (Series B), 6, pp. 51-67.

2. Bhargava, D.S. (1985), Water quality variations and control technology of Yamuna river, Environmental Pollution (Series A), 37, pp. 355-376.

3. Canadian Council of Ministers of the Environment (2001), Canadian water quality guidelines for the protection of aquatic life, Canada.

4. Clesceri, L.S., Greenberg, A.E., and Eaton, A.D. (1998), Standard method for the examination of water and wastewater, 20th Ed., APHA, USA.

5. Hop N.V., Long H.T., Lieu, P.K., Tung, T.Q., Phong, N.H., and Binh, T.T. (1999), Present status of water environment in Thua Thien Hue province 1994 - 1998, Scientific Report, Thua Thien Hue Department of Science, Technology and Environment, Hue (in Vietnamese).

6. Ministry of Science, Technology and Environment (2002), Vietnamese standard for environmental quality - Water quality, Vol. 3 and 4, Ha Noi (in Vietnamese).

7. Nelson, F., Alberto, R.R., and Fredy, S. (2004), Physico - chemical water quality indices - a comparative review, Revisal BISTUA, Colombia, pp. 19-30.

8. Nives, S.G. (1999), Water quality evaluation by index in Dalmatia, Water Research, 33, pp. 3423-3440.

9. Ott, W.R. (1978), Environmental indices - Theory and practice, Ann Arbor Science Publishing Inc. 